\title{
Exploration of Train Route of Applied Talents of Statistics in Local Colleges
}

\author{
Yan shu-xi \\ School of Mathematics and Statistics \\ Yulin University \\ Yulin 719000, China
}

\begin{abstract}
The social demand for talent is multifaceted, multilayered. Although businesses need accounting personnel, different sectors of the statistical personnel requirements vary specific to the actual work. At present, most institutions have opened statistically professional training objectives. Different institutions have different applied talents statistically professional training in local colleges. They have particularity. That is to distinguish applied talents in vocational colleges, but it is also different from the training model applied academic research institutions.
\end{abstract}

\section{Keywords- applied talents; connotation; ability; path}

\section{INTRODUCTION}

The connotation of an accounting professional applications talents definition of social demand for talent is multifaceted, multi-layered. Although businesses need accounting personnel, the different sectors of the accounting personnel requirements vary specific to the actual work. Currently, the majority of our institutions have set up the accounting profession. Different institutions have different training objectives. Local Colleges accounting professional training applied talents have its particularity. That is, to distinguish Applied Talents vocational colleges. But it is also different from the training model applied academic research institutions. Distinguished academic research universities have good academic research university students' quality of the accounting profession, a strong student comprehension and learning ability. Even in undergraduate education level, students should also have a strong ability to update their knowledge. A considerable number of students choose to continue their studies and hope to become the industry's elite. Applied Talents have all kinds of institutions, emphasizing the application of theory, culture theory talents. Education task tends to strengthen basic research. Students focus on study skills and ability to continue learning. Curriculum system changes from imparting knowledge-based steering students' qualities and abilities emphasizing knowledge of cutting-edge achievements in the professional expertise to participating in research activities of teachers. Students on the basis of careful study of accounting theory make efforts to improve the practical ability. Different from vocational colleges, applied talents in vocational colleges emphasize the use of the skills, training or technical skill talents. Vocational colleges teaching in the organization should pay more attention to the practice of teaching. To train to understand the theory, applications will operate technical and skilled personnel. Employment targets are mainly located in the front-line accounting positions, in personnel training in vocational skills-based, requiring students' knowledge and skills to meet the requirements of the employer's professional positions, familiar with accounting regulations. Accounting system should be able to complete a good accounting. Afterwards, reimbursement and other accounting work daily accounts. The difference between the local ordinary colleges and universities should be between the first two categories institutions, namely professional applications ranging talents and skills according to its own characteristics, training applied talents applied theory. The purpose of personnel training requirements has strong adaptability to serve the regional economic development, to be with the local economic structure and industrial structure closely, emphasizing relatively complete theoretical system. While strengthening the theoretical study particularly focuses on students' application ability. Local professional training colleges of applied accounting personnel and vocational colleges compared to the more technical personnel who have "wide" and "special" knowledge structure. They have a stronger ability to learn and job adaptability and more practical application ability. They can quickly adapt to the needs of the post. Such personnel training objectives should be "based on generalist professionals", which requires the system to acquire specialized knowledge of accounting, accounting proficient and proficient knowledge of accounting requirements related to economics, management, accounting, finance, etc., from multi-perspective to analysis and solving accounting problems.

\section{The Statistical Training Mode}

Training mode concept has many interpretations. "Training mode" refers to certain modern educational theory, educational thought, according to a specific training objectives and personnel specifications to a relatively stable teaching content and curriculum, management system and assessment methods, the implementation process of talent education sum. Content general training model should include the training objectives, training programs, training resources, training methods, training and quality control and other ways. It specifically includes four meanings: raising goals and specifications, to achieve certain training objectives and specifications of the entire educational process, to achieve a set of management and evaluation system in this process and science teaching methods to match the method and means. If the simplified formula, namely: Target + Process and Methods (course content and 
curriculum management and assessment system ++ teaching methods and methods). Higher quality of personnel training has two evaluation scales. First, we evaluate the quality of community college training of personnel. As the main evaluation criteria, the quality of graduates are the quality of community college graduates overall rating. The main concern is whether the social graduates to meet the needs of today's society and the market. So basically do not care about the internal university teaching activities. Second, the main feature of the school's own evaluation of the quality of talent cultivation is the quality of education and teaching as evaluation criteria. A graduate of the school concerned has not reached the professional schools to develop training objectives. Whether the quality of graduates and school culture training objectives unanimously. From the point of view of their own universities, to improve the quality of personnel training is to improve the training of personnel and training objectives in line with the degree to improve talent degree of adaptation to society.

For colleges and universities, talent training mode reform should include the following: to foster a community based on the need for professional settings and professional goals and to develop specifications to be adjusted to follow the law of the external relations of education, personnel training to make better adapt to economic and social development needs. Two professional training objectives, training specifications as a reference, follow the law of the internal relations of education. Professional training programs adjust to cultivate ways to improve the quality of personnel training and training objectives of the degree of compliance. After the training model implemented, the result is to cultivate the culture of the type, size and quality of talent. According to the two training quality personnel evaluation scale, these culture results were fed back to the school and the community. Mainly to see the quality of school graduates have not reached the goal of professional training requirements. And society is mainly to see whether graduates meet the needs of economic and cultural development of the local community at present. If graduates cannot meet the needs of the local community development, school personnel must be on training objectives, specifications and training programs, and other ways to re-adjust, that is talent training mode to adjust.

\section{THE PURPOSE AND SIGNIFICANCE OF THE EXPLORATION}

The purpose of exploring is the popularization of higher education on the road to development. The quality of education raises more and more people's attention. What kind of talent for training, how to train personnel and other issues has been a matter of great importance. With the rapid development of China's higher education, the original local colleges and later upgraded the local colleges. Higher education services become the main force in the local economy, "because of the special nature of the service area of the location of the institutions specificity, resulting in personnel training mode has a specific purpose. Personnel training specifications and common key institutions are very different. "In general, the applied talents training is the main objective of talent cultivation local Colleges' place Schools should be based on the actual location and economic environment of the school to determine the local colleges positioned to develop appropriate training specifications. " This paper attempts to begin by analyzing the applied talents training process and the current status quo of local talent training colleges, learn advanced experience, the proposed colleges of applied training model unique, in terms of culture connotation local Colleges applied talents goals. We expect a rich university personnel training theory. In practice, local talent training colleges provide reference.

We analyze the existence of common problems "Combined with China's national conditions and the actual running of these institutions in their school practice, we propose appropriate development strategies, to promote its smooth running" simultaneously through our development of new local colleges' situation analysis, to explore common problems of external environment and internal process of running their survival encountered, and propose practical solutions to common problems in running these institutions encountered during practice, prompting the development of higher education in China. In short, in theory and practice or at the macro and micro aspects, the new issue systematic study of undergraduate colleges of applied training model has important theoretical and practical significance.

\section{THE ANALYSIS OF STATUS QUO AND PROBLEMS OF STATISTICS IN LOCAL COLLEGES}

As the nascent era of mass higher education institutions, the new place is far from being a relatively mature undergraduate education practice system, the development of practical teaching requirements still lags behind its connotation construction. Due to the new mechanism in the past, local colleges teaching mainly results in their practice teaching system. Usually there will be some problems. Local newly through information collected and recycled to the questionnaire statistics, we found that the practice of teaching system in the implementation process, or there are some problems:

\section{A. Training Target Positioning Is Not Clear}

The fundamental survival and development of a higher education institution is that it can adapt to the culture and social development needs of talent. So in order to continue to develop healthy, the key of a university is to set out the professional training required in order for the community. Because the new school history is shorter local colleges from the school's discipline construction, faculty, quality of students, teaching standards and traditions of the school and other terms, it is difficult to cultivate top-notch talent level of theory. And social development requires not only a certain number of theoretical talents, but also needs to engage in the practice of a large number of job applications talents. The new local universities such talent is the training institutions.

Lack of Building the System of Practice Teaching System

Currently, a number of new local universities in the process of running did not follow its own characteristics to construct the teaching system. Many places still imitate a 
veteran of the colleges. Heavy theory, light practice remains the widespread problem in their education system.

\section{B. The Attention Paid to Connotation Construction of Program Is Not enough}

Relationship connotation construction and extension of development cannot cart before the horse. You should rely on the connotation of progress leading to extension of development, rather than to expand the extension, so that the connotation of passive stretch to fill. New local colleges for undergraduate courses connotation construction, some people feel unable to start. Faster is better to catch epitaxial construction and easy to produce good results. For example, in the college admissions process, some of the universities do not have the enrollment conditions "virtual real power to do", eyes fixed on the extension efforts, the building that covered everything will be fine. The pursuit of the so-called scale waits until students flocked connotation construction. It cannot keep up. There has been a series of problems. Quality of training of students cannot be guaranteed. Connotation construction concrete manifestation implements the curriculum development.

\section{Hands-on Teaching Staff Is Relatively Weak}

Through questionnaires and interviews with teachers and students, we reached the following conclusions. Currently, many schools affected by the traditional concept of "heavy theory, light practice", reflected in the practice of the faculty building. It is yet to pay attention to this problem. Specific performance is as follows: First, the practice of teaching teachers is more from the theory teachers to serve, only with a little practice full-time teachers. Full-time teachers and teaching practice in schools is generally referred to teaching assistants. Education level is not high. The knowledge and the ability compare a single structure. Practice teaching staff from enterprises to introducing some schools, without professional teaching theoretical study, often misses in terms of means and methods of teaching. Therefore, it will affect the conduct of the practice of teaching and learning activities. Second, the school does not have practical teaching teachers to mobilize the initiative and enthusiasm of an effective incentive and competition. Third, to improve the quality of teachers, many schools do not pay attention to the practice of teaching and research activities, there is no specific research project, a number of studies have generally not supported spontaneous funding. Resulting in teacher enthusiasm is not high, resulting in lack of research on teaching practice, which could result in the practice of teaching quality. It is difficult to be assured. The overall quality of practice teaching full-time teachers is not improved.

\section{CONCLUSIONS}

Based on the statistics of local colleges and reading relevant literature on representative and the questionnaire institutions, interviews surveys on issues of practice teaching system were studied. Author gets insight into the practical teaching system of local colleges. New problems, such as personnel training targeting, are not clear. There is a lack of practice teaching plan and no perfect security system. The author explored the research based on talent development theory, Marx's theory of combining education and production, the theory of multiple intelligences theory, pragmatism educational theory. It also conducted a preliminary inquiry to build the Practice Teaching System in new place.

\section{References}

[1] He Qingguang. Research and Practice of Applied Talents of Statistics [J]. Occupation Space, 2010,08: 79-81.

[2] Han Yue. Exploration of Cultivating Integrated Talent of Application Management --ERP System in Teaching [J]. Technology Rich Wizard, 2009,12: 94-95.

[3] Zeng Yuhong. Exploration of Cultivating Talent of Foreign Language under the New Situation [J]. Everyone, 2012,09: 225.

[4] Yao Yazhi. Training of Local Interpreters: Take, the Practice of European and American Universities, for example [J]. LITERATURE (Foreign Language Education and Teaching), 2011,01: 101-103 + 105.

[5] Feng Suhong, Liu Pei, Xu Min, Li Xifeng, Bai Yan. Building a Multimodule Pharmacy Practice Teaching Mode to Cultivate Innovative Talents [J]. Laboratory Research and Exploration, 2011, 01: 129-131.

[6] Liu RenShan. The Cultivation of Legal Professionals in the context of Globalization [J]. Legal Science (Journal of Northwest University of Political Science), 2011,02: 195-200.

[7] Liu Zhiyun. Training Objectives, Training Mode and Key Points of Implementation of Creative Talents [J]. Chinese University Teaching, 2011,01: 12-15. 